\title{
The Dr Lindsay E Nicolle Award
}

$\mathrm{T}_{\mathrm{t}}^{\mathrm{h}}$ he 2009 winner of the Dr Lindsay E Nicolle Award was announced by Robert Kalina, Publisher of The Canadian Journal of Infectious Diseases $\mathcal{E}$ Medical Microbiology, at the recent International Congress of Chemotherapy and Infection, incorporating the AMMI Canada-CACMID annual conference, in Toronto, Ontario. The winner was Dr Abba Gumel for his paper "Mathematical assessment of Canada's pandemic influenza preparedness plan" (Can J Inf Dis Med Microbiol 2008;19[2]:185-192).

This award is funded by Pulsus Group in honour of Dr Lindsay E Nicolle, the founding Editor-in-Chief of The Canadian Journal of Infectious Diseases \& Medical Microbiology. It is given annually to an individual who made a significant contribution to the field of infectious disease, as demonstrated by the impact of original research published in The Canadian Journal of Infectious Diseases $\mathcal{E}$ Medical Microbiology and judged by the Editor-in-Chief and Associate Editors. The award consists of $\$ 1,000$ and a Canadian work of art.

Robert Kalina also presented a cheque to Richard McCoy, Executive Director of AMMI Canada. The Canadian Journal of Infectious Diseases $\mathbb{E}$ Medical Microbiology is the official journal

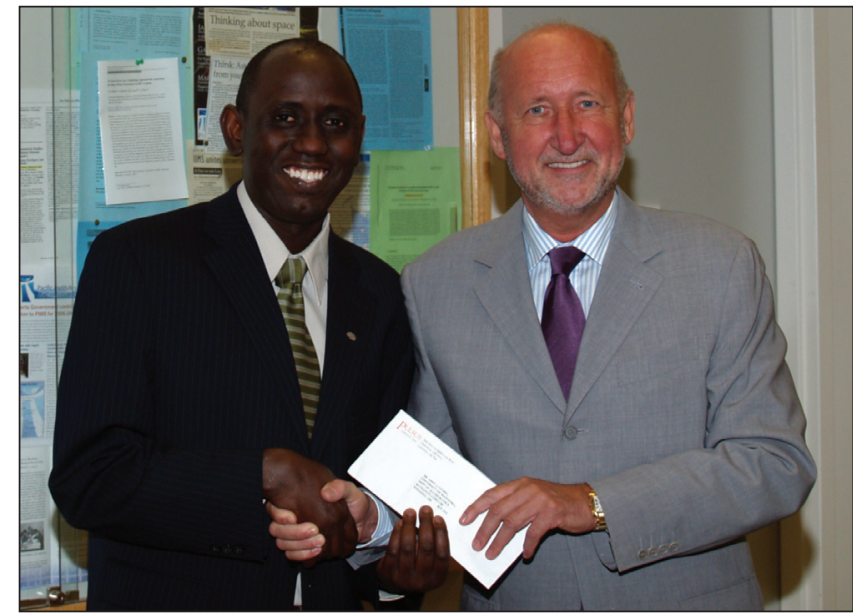

Robert Kalina, Publisher (right), presents a cheque to Dr Abba Gumel, winner of the Dr Lindsay E Nicolle award

of AMMI Canada, and each year, Pulsus Group contributes a percentage of revenues derived from the Journal to the Society for use in future research. 


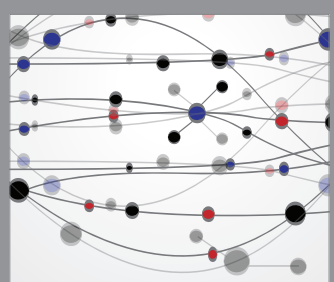

The Scientific World Journal
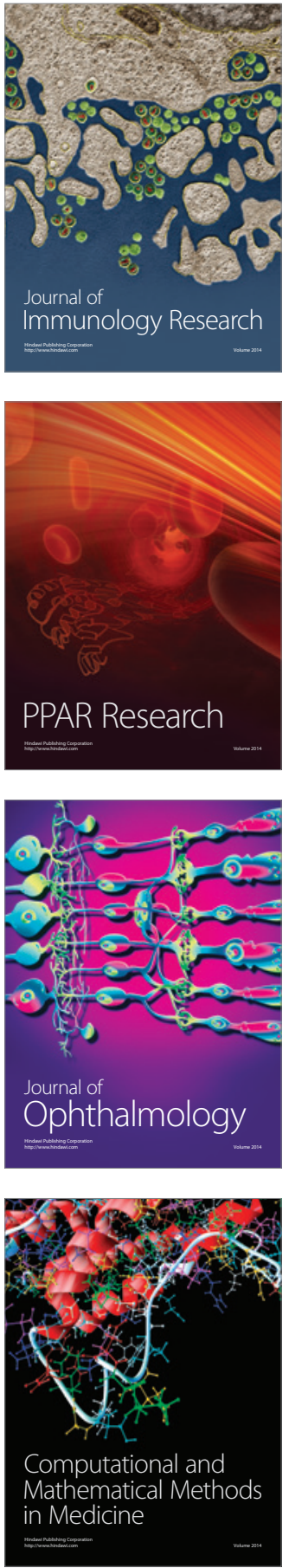

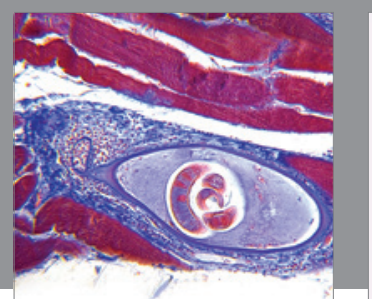

Gastroenterology Research and Practice

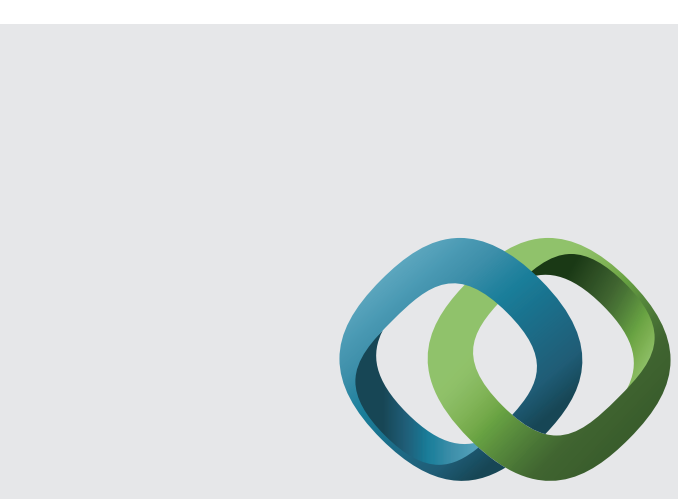

\section{Hindawi}

Submit your manuscripts at

http://www.hindawi.com
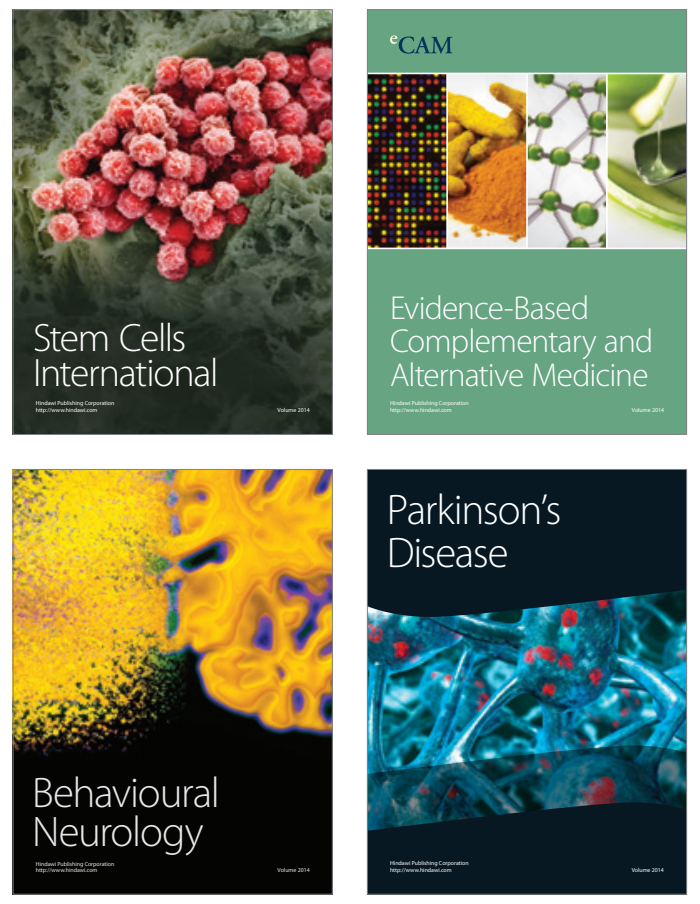
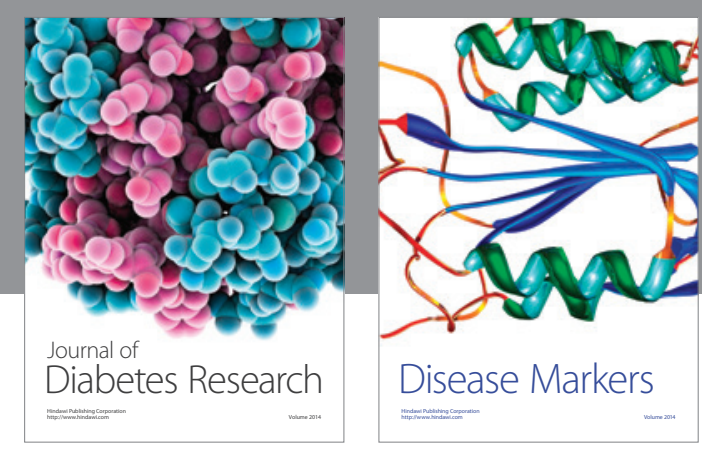

Disease Markers
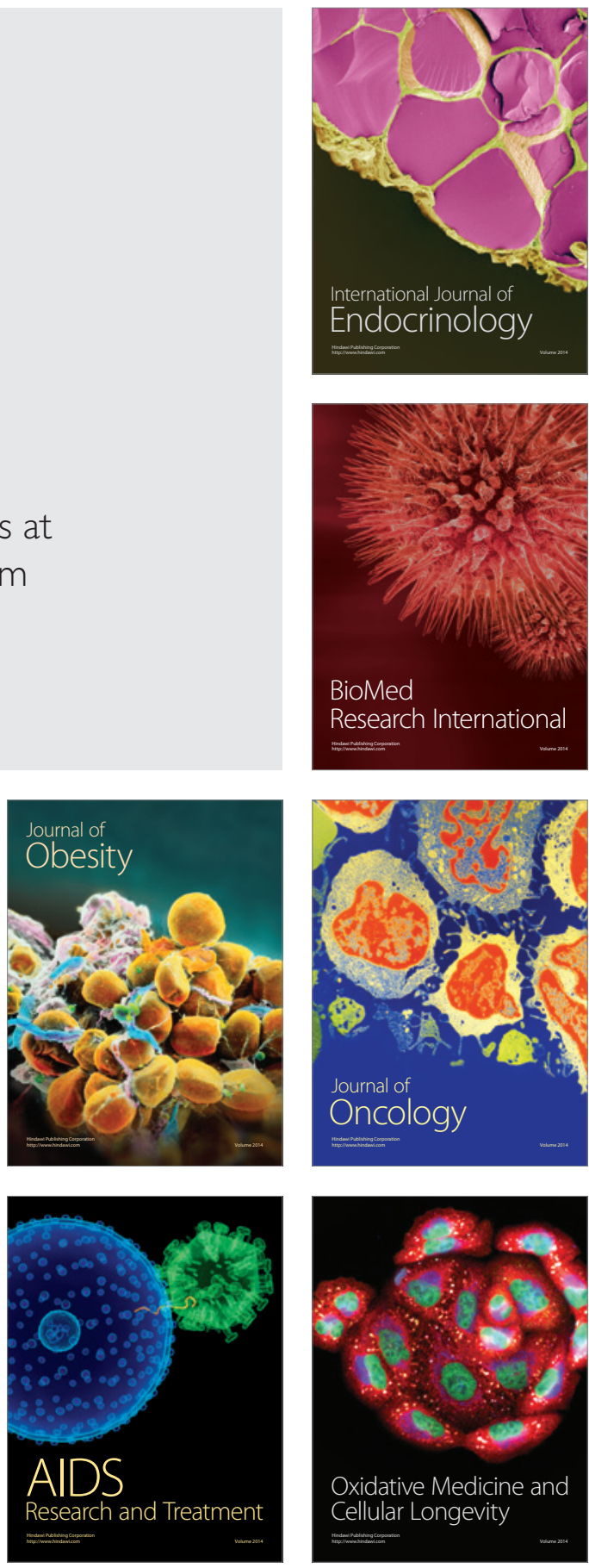